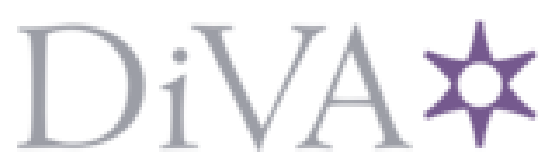

http://www.diva-portal.org

This is the published version of a paper published in Applied Physics Letters.

Citation for the original published paper (version of record):

Kaihovirta, N., Longo, G., Gil-Escrig, L., Bolink, H., Edman, L. (2015)

Self-absorption in a light-emitting electrochemical cell based on an ionic transition metal complex.

Applied Physics Letters, 106(10)

http://dx.doi.org/10.1063/1.4914307

Access to the published version may require subscription.

N.B. When citing this work, cite the original published paper.

Permanent link to this version:

http://urn.kb.se/resolve?urn=urn:nbn:se:umu:diva-102367 


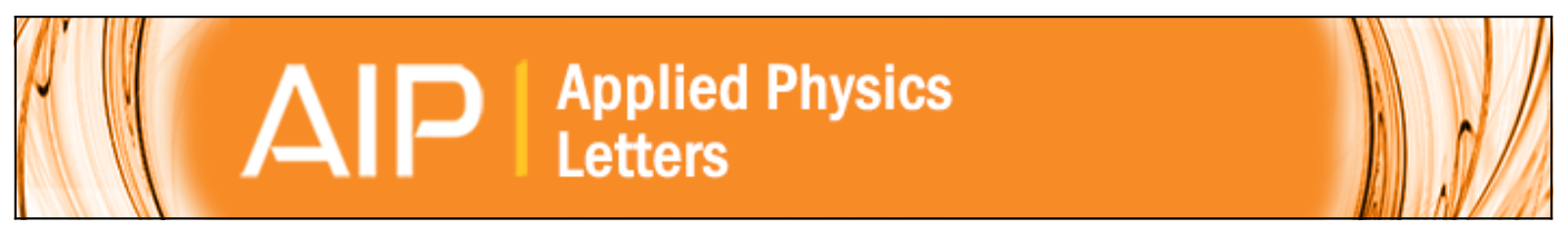

\section{Self-absorption in a light-emitting electrochemical cell based on an ionic transition metal complex}

Nikolai Kaihovirta, Giulia Longo, Lidón Gil-Escrig, Henk J. Bolink, and Ludvig Edman

Citation: Applied Physics Letters 106, 103502 (2015); doi: 10.1063/1.4914307

View online: http://dx.doi.org/10.1063/1.4914307

View Table of Contents: http://scitation.aip.org/content/aip/journal/apl/106/10?ver=pdfcov

Published by the AIP Publishing

\section{Articles you may be interested in}

The dynamic behavior of thin-film ionic transition metal complex-based light-emitting electrochemical cells J. Appl. Phys. 116, 104504 (2014); 10.1063/1.4895060

Optically pumped amplified spontaneous emission in an ionic liquid-based polymer light-emitting electrochemical cell

Appl. Phys. Lett. 100, 263301 (2012); 10.1063/1.4730948

Efficient solid-state host-guest light-emitting electrochemical cells based on cationic transition metal complexes Appl. Phys. Lett. 89, 261118 (2006); 10.1063/1.2425008

Lifetime study of polymer light-emitting electrochemical cells

J. Appl. Phys. 100, 084501 (2006); 10.1063/1.2357862

Recombination profiles in poly[2-methoxy-5-(2-ethylhexyloxy)-1,4-phenylenevinylene] light-emitting electrochemical cells

J. Appl. Phys. 98, 124907 (2005); 10.1063/1.2149162

Frustrated by

old technology?

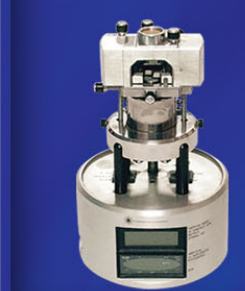

Is your AFM dead

and can't be repaired?

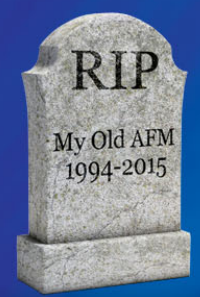

Sick of bad customer support?

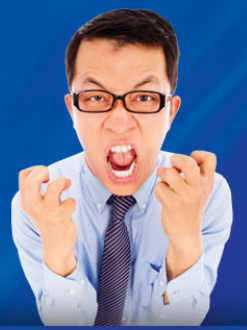

It is time to upgrade your AFM Minimum $\$ 20,000$ trade-in discount for purchases before August 31st

Asylum Research is today's technology leader in AFM 


\title{
Self-absorption in a light-emitting electrochemical cell based on an ionic transition metal complex
}

\author{
Nikolai Kaihovirta, ${ }^{1}$ Giulia Longo, ${ }^{2}$ Lidón Gil-Escrig, ${ }^{2}$ Henk J. Bolink,${ }^{2}$ and Ludvig Edman ${ }^{1, a)}$ \\ ${ }^{1}$ Department of Physics, The Organic Photonics and Electronics Group, Umeå University, SE-90187 Umeå, \\ Sweden \\ ${ }^{2}$ Instituto de Ciencia Molecular, Universidad de Valencia, c/Catedrático J. Beltrán, 2, 46980 Paterna, Spain
}

(Received 5 February 2015; accepted 25 February 2015; published online 11 March 2015)

\begin{abstract}
We report on the quantitative and qualitative effects of self-absorption in light-emitting electrochemical cells (LECs) based on ionic transition metal complexes (iTMCs), as measured in-situ during electric driving. A yellow-emitting iTMC-LEC comprising an active material thickness of $95 \mathrm{~nm}$ suffers a $4 \%$ loss of the emission intensity to self-absorption, whereas the same type of device but with a larger active-material thickness of $1 \mu \mathrm{m}$ will lose a significant $40 \%$ of the light intensity. We also find that the LEC-specific effect of doping-induced self-absorption can result in a drift of the emission spectrum with time for iTMC-LECs, but note that the overall magnitude of doping-induced selfabsorption is much smaller than for conjugated-polymer LECs. C 2015 AIP Publishing LLC.
\end{abstract}

[http://dx.doi.org/10.1063/1.4914307]

Organic electroluminescent (EL) devices are currently developing into a viable option for a wide range of display and lighting applications, with the current success story being the commercial introduction of the organic light-emitting diode as the high-end display in cell phones. ${ }^{1}$ The lightemitting electrochemical cell (LEC) ${ }^{2,3}$ is an alternative and less studied organic EL device, which recently has attracted increased interest due to its simple and fault-tolerant device structure, improvements in performance, ${ }^{4}$ and developments towards industrial-scale manufacturing. ${ }^{5}$ Two main classes of LEC-devices can be identified: (i) the conjugated polymer LEC (CP-LEC) $)^{2,6}$ and (ii) the ionic transition metal complex LEC (iTMC-LEC). ${ }^{7-9}$ The active material in CP-LECs is composed of an EL conjugated polymer intermixed with an electrolyte, where the former performs the tasks of electron transport and light emission and the latter allows for ion transport. The iTMC can in contrast perform all of these LEC-fundamental tasks within one single material (although a second electrolyte is commonly added to shorten the turnon time).

The architecture of a functional LEC can be very simple in that it comprises a solution-processed single-layer active material sandwiched between a hole-injecting anode and an electron-injecting cathode. Following the application of a voltage between the electrodes, the mobile ions in the active material drift and accumulate at the electrode interfaces under the formation of electric double layers, which in turn facilitate for efficient electronic charge injection into the active material. The first injected electronic charge carriers are electrostatically screened through the motion of chargecompensating ions in a process termed electrochemical doping: p-type doping takes place at the anode and n-type doping at the cathode, and eventually a light-emitting $p-n$ junction forms in the bulk of the active material. ${ }^{10,11}$

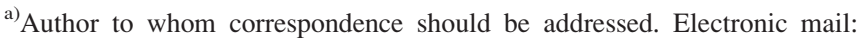
ludvig.edman@physics.umu.se
}

The unique in-situ electrochemical doping mechanism of LECs has been demonstrated to enable for a number of attractive features, notably efficient and balanced electron/ hole injection from two air-stabile electrode materials, ${ }^{11}$ the utilization of thick and fault-tolerant active materials, ${ }^{12}$ and the employment of simple-to-fabricate device architectures. ${ }^{13}$ However, it also brings a number of drawbacks and challenges, and in a recent study on CP-LECs we demonstrated that doping-induced self-absorption can be a highly performance-limiting effect, particularly if thick active materials with high levels of doping are used. ${ }^{14}$ More specifically, as the conjugated polymer becomes electrochemically doped during the initial LEC operation, its absorption profile changes so that it begins to overlap strongly with the EL spectrum, and as a result absorb more of the photons generated in the $\mathrm{p}$-n junction region. ${ }^{14,15}$

In order to be able to design high-performance LEC devices with rational means, it is thus motivated to investigate the effects, and establish the amount, of self-absorption in iTMCLECs. In contrast to the situation in CP-LECs we find that doping-induced self-absorption is of relatively small magnitude for such devices, although it can result in an undesired drift of the emission color with time (and increasing amount of doping). However, the total effect of self-absorption can still be significant, and we find that for a yellow-emitting iTMC-LEC the loss is $4 \%$ for an active-material thickness of $95 \mathrm{~nm}$, and a staggering $40 \%$ for devices with an active material thickness of $1 \mu \mathrm{m}$.

The device fabrication was executed as follows. An indium-tin-oxide (ITO) coated glass substrate (Naranjo) was prepared by sequential sonication in detergent, distilled water and isopropanol, flushing of $\mathrm{N}_{2}$ gas, and exposure to UVozone. A $60 \mathrm{~nm}$ thick layer of poly(3,4-ethylenediethoxythiophene):poly(styrene sulphonate) (PEDOT:PSS) (Clevios P VP AI 4083, Heraeus) was spin-coated on top of the ITO, and dried at $T=150{ }^{\circ} \mathrm{C}$ for $15 \mathrm{~min}$. The active material is a blend of the iTMC 2-phenylpyridine 4,4'-di-tert-butyl-2,2'-dipyridyl iridium(III) hexafluorophosphate $\left[\operatorname{Ir}(\mathrm{ppy})_{2}(\mathrm{dtb}-\mathrm{bpy}): \mathrm{PF}_{6}\right]$ and 
(a)
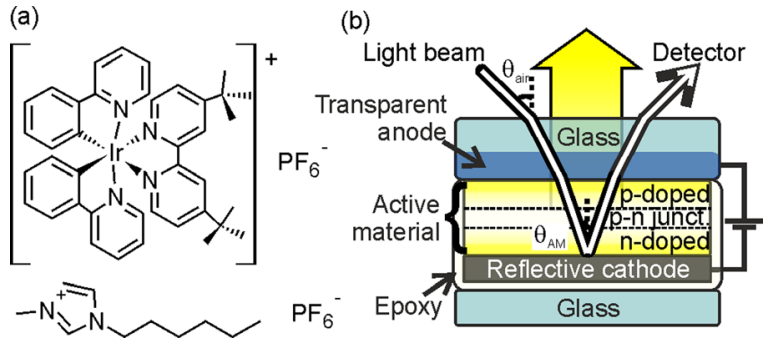

FIG. 1. (a) The chemical structure of the $\operatorname{Ir}(\mathrm{ppy})_{2}(\mathrm{dtb}-\mathrm{bpy}): \mathrm{PF}_{6}$ complex and the BMIM: $\mathrm{PF}_{6}$ ionic liquid constituting the active material. (b) The experimental set-up for the in-situ characterization of self-absorption during LEC operation.

the ionic liquid 1-butyl-3-methylimidazolium hexafluorophosphate (BMIM:PF 6 , Aldrich) in a 4:1 molar ratio. The chemical structure of the active-material constituents is presented in Fig. 1(a). Details on the synthesis of $\left[\operatorname{Ir}(\mathrm{ppy})_{2}(\mathrm{dtb}-\mathrm{bpy})\right]\left[\mathrm{PF}_{6}\right]$ have been reported elsewhere, ${ }^{9}$ and the ionic liquid was added in order to shorten the turn-on time. ${ }^{16}$ A $95 \mathrm{~nm}$ thick layer of active material was spin-coated from a $20 \mathrm{mg} / \mathrm{ml}$ acetonitrile solution. The coated substrate was thereafter transferred into a $\mathrm{N}_{2}$-filled glove box $\left(\left[\mathrm{O}_{2}\right],\left[\mathrm{H}_{2} \mathrm{O}\right]<1 \mathrm{ppm}\right)$ and dried on a hot plate at $T=90^{\circ} \mathrm{C}$ for $1 \mathrm{~h}$. A $70 \mathrm{~nm}$ thick Al cathode was deposited by thermal evaporation at $p<3 \times 10^{-6}$ mbar, with a shadow mask defining the size of the cathode and the emission area. For ambient-air operation, the LECs were encapsulated by attaching a glass plate onto the Al-side of the device with a UV-curable single-component epoxy adhesive (Ossila). ${ }^{17}$ The encapsulated LEC-structure is shown in Fig. 1(b).

The LECs were operated at a voltage of $V=4 \mathrm{~V}$, with ITO biased as the positive anode. For the device characterization, the LECs were driven, and the current recorded, by a computer-controlled source-measure unit (U2722A, Agilent), while the luminance was measured with a calibrated photodiode equipped with an eye-response filter (Hamamatsu). This measurement was executed on non-encapsulated devices with an emission area of $0.15 \times 0.85 \mathrm{~cm}^{2}$ in the glove box. The absorption spectrum of the pristine active material was recorded at normal incidence with a UV-Vis absorption spectrometer (Lambda 35, PerkinElmer). The setup for the in-situ measurement of the change in absorption, and for the recording of the EL spectrum (in the normal direction), during operation is depicted in Fig. 1(b) and is described in detail in Ref. 14. These LECs were driven by a computer-controlled sourcemeasurement unit, and the absorption and EL spectra were averages of 100 scans, with the integration time of each scan being $10 \mathrm{~ms}$ (absorption) or $50 \mathrm{~ms}$ (EL). The in-situ EL and absorption measurements were performed on encapsulated devices with an emission area of $0.59 \times 0.60 \mathrm{~cm}^{2}$ operating under ambient air.

Fig. 2(a) shows the temporal evolution of the current efficacy $(C E)$, the luminance $(L)$, and the current density $(j)$ during the initial operation of a pristine device. The LEC emitted detectable light $\left(L>1 \mathrm{~cd} / \mathrm{m}^{2}\right)$ within $2 \mathrm{~min}$, and "turns on" $\left(L>100 \mathrm{~cd} / \mathrm{m}^{2}\right)$ after roughly $7 \mathrm{~min}$. The device first peaked in efficiency, then in luminance and finally in current, which is the common trend for functional LECs. ${ }^{18}$ We find that the iTMC-LECs operate in a reversible fashion up to the time of maximum current, and have therefore
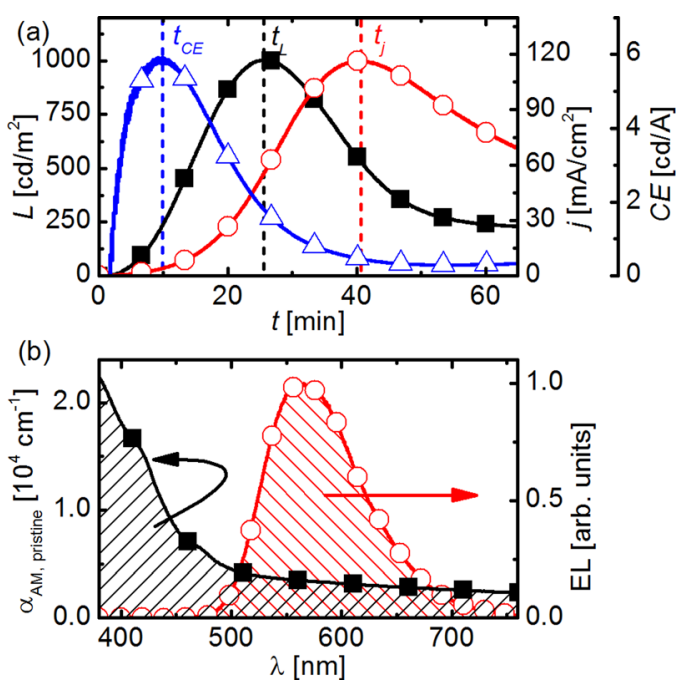

FIG. 2. (a) The temporal evolution of the current efficacy (open blue triangles), luminance (solid black squares), and the current density (open red circles) of an LEC driven at $\mathrm{V}=4 \mathrm{~V}$. (b) The absorption spectrum for the pristine active material (solid black squares) and the EL-spectrum of the LEC at maximum luminance (open red circles).

chosen to focus our attention on this time regime. Moreover, in order to facilitate a comparison between the different measurements, and to effectively eliminate obscuring effects due to minor device-to-device variations, we have in the subsequent opted to normalize the time to that of the maximum current density, i.e., $t_{j}=1$.

The absorption spectrum of the pristine active material in the visible regime is shown in Fig. 2(b) (solid black squares). We observe a significant and broad absorption band below $475 \mathrm{~nm}$, which is assigned to metal-to-ligand and ligand-to-ligand charge-transfer transitions, ${ }^{8}$ and an absorption tail that spans the reminder of the visible region. It is notable that the active material in a typical yellowemitting CP-LEC features a much stronger absorption in the visible regime, ${ }^{14}$ as manifested in a higher absorption coefficient and a more opaque active material at the same thickness. The herein studied 95-nm thick active material is relatively transparent with a faint yellowish hue to the eye.

The EL spectrum from the iTMC-LEC operating at maximum luminance is presented in Fig. 2(b) (open red circles). We find that the device features a rather broad EL spectrum in the range between 500 and $680 \mathrm{~nm}$, with the emission peak located at $\lambda_{\text {EL-peak }}=566 \mathrm{~nm}$. We note that the EL spectrum is positioned in a wavelength region where the pristine active material is absorbing, as illustrated by the overlap of hatched areas in Fig. 2(b). As the emission zone in this type of sandwich-cell device commonly, and desirably, is positioned in the middle part of the active material, this implies that some of the light generated in the emission zone will be "self-absorbed" on its way out of the device, when it passes (at least) one region of absorbing active material.

Moreover, a characteristic feature of a LEC is that the active material is electrochemically doped at the two electrode interfaces during the initial operation, and that a light-emitting p-n junction doping structure has formed at significant light emission. In this scenario, the emission zone is coinciding 
with the p-n junction, and the light generated in the p-n junction has to pass at least one doped region before exiting the device (see Fig. 1(b)). The doping process can cause distinct changes of the absorption profile of the doping regions, and we have recently demonstrated that this effect can result in a significant doping-induced self-absorption in CP-LECs. ${ }^{14}$

For the measurement of this effect in an iTMC-LEC, that is the change in absorption during device operation, we have employed the setup displayed in Fig. 1(b). The probing light beam is incident on the device with an angle of $\theta_{\text {air }}$ and travels through the active material twice before reaching the detector. The optical path length the probing light beam has then traversed through the active material can be calculated with the aid of Snell's law and some basic math

$$
\mathrm{OPL}_{\mathrm{AM}}=2 \times d_{\mathrm{AM}} /\left(\cos \left(\arcsin \left(n_{\text {air }} \times \sin \left(\theta_{\text {air }}\right) / n_{\mathrm{AM}}\right)\right)\right)
$$

where $d_{\mathrm{AM}}$ is the thickness of the active material, $n_{\text {air }}(=1)$ and $n_{\mathrm{AM}}\left(\approx n_{\mathrm{iTMC}}=1.8\right)^{19}$ are the refractive indices of air and the active material, respectively, and $\theta_{\text {air }}\left(\right.$ here, $\left.45^{\circ}\right)$ is the angle of incidence with respect to the normal.

If we further assume that the p-n junction is $10 \mathrm{~nm}$ thick, and that the $\mathrm{p}$ - and $\mathrm{n}$-doped regions are equally thick, we find that the optical path length through the doping regions is: $\mathrm{OPL}_{\mathrm{dop}}=\left[\left(d_{\mathrm{AM}}-10 \mathrm{~nm}\right) / d_{\mathrm{AM}}\right] \times \mathrm{OPL}_{\mathrm{AM}}$. By plugging in $d_{\mathrm{AM}}=95 \mathrm{~nm}$ for the thickness of the active material, we find that $\mathrm{OPL}_{\mathrm{dop}}=185 \mathrm{~nm}$. By making the assumption that the effects of doping on absorption is equal throughout both the doping regions, we can calculate the change in the absorption coefficient as: $\Delta \alpha_{\mathrm{AM}}(\lambda)=\Delta A(\lambda) / \mathrm{OPL}_{\mathrm{dop}}$, where $\Delta A(\lambda)$ is the measured change in the absorbance during doping as a function of wavelength.

Fig. 3(a) presents the temporal evolution of $\Delta\left(\alpha_{\mathrm{AM}}\right)$ at three different wavelengths: $\lambda=525 \mathrm{~nm}$ (solid blue squares), $\lambda=566 \mathrm{~nm}$ (open black circles, corresponding to the EL peak) and $\lambda=675 \mathrm{~nm}$ (solid red triangles). We find that the onset of significant doping-induced absorption is located in between the times of peak luminance and peak current. Interestingly, we find that the effects of the doping-induced self-absorption are distinctly different than for a CP-LEC. We have found that $\Delta\left(\alpha_{\mathrm{AM}}\right)$ at the EL-peak wavelength for a CP-LEC could reach $2-3 \times 10^{4} \mathrm{~cm}^{-1}$ in the reversible regime, which is more than one order of magnitude larger than for the iTMC-LEC. Thus, it seems like the doping has less of an influence on the optical properties of the iTMC in comparison to a conjugated polymer.

Moreover, we find that the doping-induced self-absorption in iTMC-LECs, in contrast to the situation for CPLECs, features a rather significant wavelength dependence. For the investigated wavelength region, we also find that the doping-induced self-absorption onset takes place earlier, and remains stronger, the shorter the wavelength. Such a wavelength-dependent temporal change of the absorption profile is expected to be manifested as a time-dependent "color-filter" effect on the EL spectra. More specifically, we anticipate that the EL intensity will drop faster for shorter wavelengths than for longer wavelengths during the final stages of the electrochemical doping process. Indeed, such a wavelength-dependent change for the EL intensity is
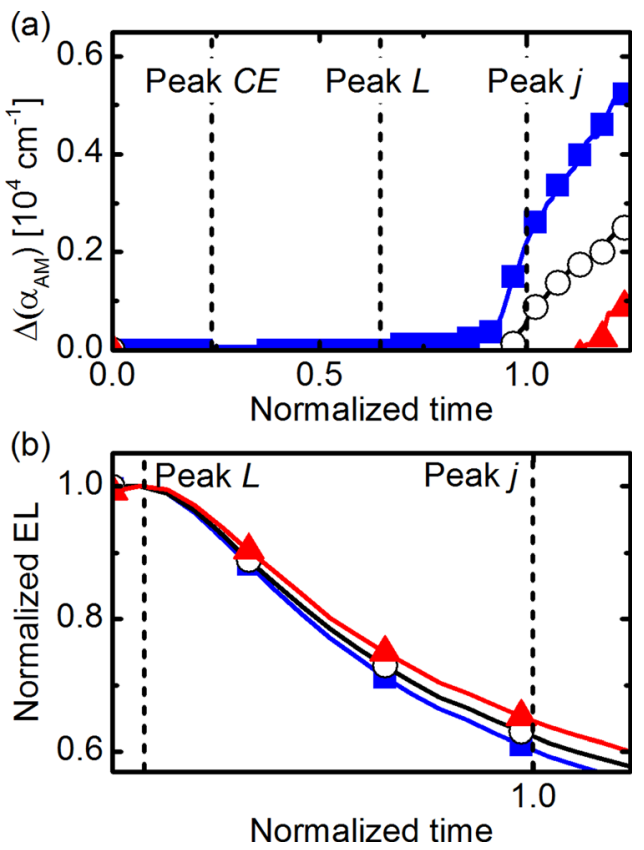

FIG. 3. (a) The temporal evolution of the doping-induced self-absorption, $\Delta\left(\alpha_{\mathrm{AM}}\right)$, at three different wavelengths: $\lambda=525 \mathrm{~nm}$ (solid blue squares), $\lambda=566 \mathrm{~nm}$ (open black circles), and $\lambda=675 \mathrm{~nm}$ (solid red triangles), with the times of the peak $\mathrm{CE}$, peak $\mathrm{L}$, and peak $\mathrm{j}$ indicated. Note that the EL peak is positioned at $\lambda=566 \mathrm{~nm}$. (b) The temporal evolution of the EL intensity from peak $\mathrm{L}$ to peak $\mathrm{j}$ for the same wavelengths.

observed during the operation of an iTMC-LEC, as shown in Fig. 3(b).

The quantitative effect of self-absorption within an LEC device can be calculated with the aid of the Beer-Lambert's law

$$
\text { Self-absorption }=1-\exp (-\alpha \times d),
$$

where $\alpha$ is the absorption coefficient and $d$ the thickness of the layer of the absorbing species. In order to address the fact that the absorption coefficient in the active material of an LEC will feature a spatial dependence during and after doping (see Figs. 3(a) and 1(b)), while at the same time keeping the analysis straightforward, we have elected to model the active material as being divided into two distinct layers: (1) the electrochemical doping regions with $\alpha_{\text {dop }}=\left(\alpha_{\mathrm{AM} \text {,pristine }}+\Delta \alpha_{\mathrm{AM}}\right)$ and (2) the doping-free p-n junc-

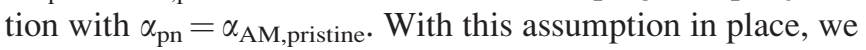
can re-write Eq. (2) as

$$
\begin{aligned}
\text { Self-absorption }= & 1-\left[\exp \left(-\alpha_{\mathrm{dop}} \times d_{\mathrm{dop}}\right)\right. \\
& \left.\times \exp \left(-\alpha_{\mathrm{pn}} \times d_{\mathrm{pn}}\right)\right] .
\end{aligned}
$$

By making the further assumption that the average photon makes one pass through the entire active material before exit, we obtain $d_{\mathrm{dop}}=\left(d_{\mathrm{AM}}-d_{\mathrm{pn}}\right)$, where we have set $d_{\mathrm{pn}}$ to $10 \mathrm{~nm}$.

We have chosen to focus our analysis on the selfabsorption at the EL peak wavelength of $\lambda=566 \mathrm{~nm}$ at the time of maximum current, and the total self-absorption loss at this wavelength as a function of active material-thickness (i.e., $d_{\mathrm{AM}}$ ) is shown in Fig. 4. We find that $4 \%$ of the emitted light is lost to self-absorption for an iTMC-LEC with a thin 


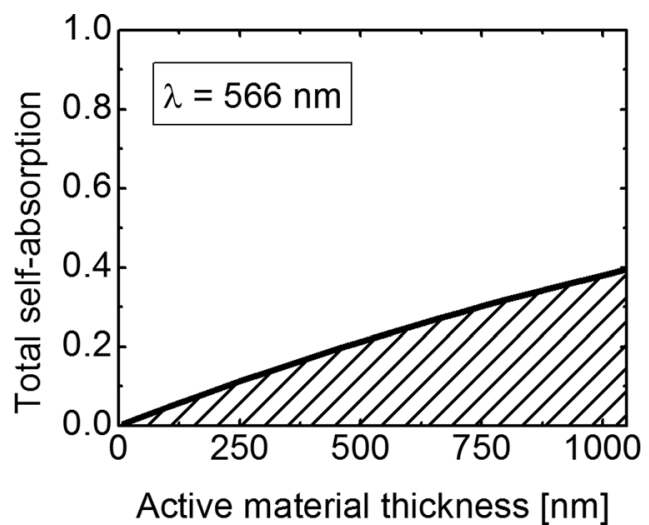

FIG. 4. The total self-absorption within an iTMC-LEC as a function of active-material thickness. Note that the self-absorption is derived for the peak EL wavelength, and at the time of maximum current.

active material of $95 \mathrm{~nm}$, as used in this study. However, if iTMC-LECs are to be fabricated with scalable production methods, such as roll-to-roll coating and printing, and the yield is to be kept at a reasonable level, it is highly feasible that thicker and more fault-tolerant active materials should be utilized. In this context, it is of interest to note that a $1 \mu \mathrm{m}$ thick active material will result in a significant loss to selfabsorption of $40 \%$ for an iTMC-LEC. We point out that the above analysis was executed under the assumption of a centered $\mathrm{p}-\mathrm{n}$ junction, but that several studies on LECs have demonstrated that the $\mathrm{p}-\mathrm{n}$ junction can be off-centered and positioned closer to one of the electrodes. ${ }^{20}$ If the $p-n$ junction is formed closer to the transparent electrode, the effects of self-absorption will be decreased, and vice versa if the p-n junction is positioned closer to the reflective electrode.

To conclude, we have quantified the different effects of self-absorption in a yellow-emitting iTMC-LEC during operation. We find that the doping-induced effects, in contrast to the situation in CP-LECs, are relatively minor, although a color-filter effect was observed to result in a slight red-shift of the emission color during operation. Nevertheless, selfabsorption can still be a significant performance-limiting factor in iTMC-LECs, and if micrometer-thick layers are to be employed during a future fault-tolerant fabrication, this effect must be considered if a peak performance is to be attained.

N.K. and L.E. acknowledge the Swedish Foundation for Strategic Research, Vetenskapsrådet, Energimyndigheten, Kempestiftelserna, Carl Trygger's Foundation and Umeå University for financial support. L.E. is a Royal Swedish Academy of Sciences Research Fellow supported by a grant from the Knut and Alice Wallenberg Foundation. The Valencian team acknowledge support from the European Union 7th framework program LUMINET (Grant No.
316906), the Spanish Ministry of Economy and Competitiveness (MINECO) (MAT2011-24594) and the Generalitat Valenciana (Prometeo/2012/053).

${ }^{1}$ S. Reineke, F. Lindner, G. Schwartz, N. Seidler, K. Walzer, B. Lussem, and K. Leo, Nature 459(7244), 234 (2009); D. Tanaka, H. Sasabe, Y. J. Li, S. J. Su, T. Takeda, and J. Kido, Jpn. J. Appl. Phys., Part 2 46(1-3), L10 (2007); C. Adachi, Jpn. J. Appl. Phys., Part 1 53(6), 060101 (2014).

${ }^{2}$ Q. Pei, G. Yu, C. Zhang, Y. Yang, and A. J. Heeger, Science 269, 1086 (1995).

${ }^{3}$ T. D. Shoji, Z. H. Zhu, and J. M. Leger, ACS Appl. Mater. Interfaces 5(22), 11509 (2013).

${ }^{4}$ H. J. Bolink, E. Coronado, R. D. Costa, N. Lardies, and E. Orti, Inorg. Chem. 47(20), 9149 (2008); D. Tordera, S. Meier, M. Lenes, R. D. Costa, E. Orti, W. Sarfert, and H. J. Bolink, Adv. Mater. 24(7), 897 (2012); D. Tordera, J. Frey, D. Vonlanthen, E. Constable, A. Pertegas, E. Orti, H. J. Bolink, E. Baranoff, and M. K. Nazeeruddin, Adv. Energy Mater. 3(10), 1338 (2013); S. Tang and L. Edman, J. Phys. Chem. Lett. 1, 2727 (2010); N. Kaihovirta, C. Larsen, and L. Edman, ACS Appl. Mater. Interfaces 6(4), 2940 (2014).

${ }^{5}$ A. Sandström, H. F. Dam, F. C. Krebs, and L. Edman, Nat. Commun. 3, 1002 (2012); A. Sandstrom, A. Asadpoordarvish, J. Enevold, and L. Edman, Adv. Mater. 26(29), 4975 (2014); G. Hernandez-Sosa, S. Tekoglu, S. Stolz, R. Eckstein, C. Teusch, J. Trapp, U. Lemmer, M. Hamburger, and N. Mechau, Adv. Mater. 26(29), 3235 (2014).

${ }^{6}$ Q. B. Pei, Y. Yang, G. Yu, C. Zhang, and A. J. Heeger, J. Am. Chem. Soc. 118(16), 3922 (1996).

${ }^{7}$ K. M. Maness, R. H. Terrill, T. J. Meyer, R. W. Murray, and R. M. Wightman, J. Am. Chem. Soc. 118(43), 10609 (1996).

${ }^{8}$ R. D. Costa, E. Orti, H. J. Bolink, F. Monti, G. Accorsi, and N. Armaroli, Angew. Chem., Int. Ed. 51(33), 8178 (2012).

${ }^{9}$ J. D. Slinker, A. A. Gorodetsky, M. S. Lowry, J. J. Wang, S. Parker, R. Rohl, S. Bernhard, and G. G. Malliaras, J. Am. Chem. Soc. 126(9), 2763 (2004).

${ }^{10}$ Y. Hu and J. Gao, J. Am. Chem. Soc. 133(7), 2227 (2011); P. Matyba, K. Maturova, M. Kemerink, N. D. Robinson, and L. Edman, Nat. Mater. 8(8), 672 (2009).

${ }^{11}$ P. Matyba, H. Yamaguchi, G. Eda, M. Chhowalla, L. Edman, and N. D. Robinson, ACS Nano 4(2), 637 (2010).

${ }^{12}$ J. Gao and J. Dane, Appl. Phys. Lett. 83(15), 3027 (2003).

${ }^{13}$ P. Matyba, M. R. Andersson, and L. Edman, Org. Electron. 9(5), 699 (2008).

${ }^{14}$ N. Kaihovirta, A. Asadpoordarvish, A. Sandstrom, and L. Edman, ACS Photonics 1(3), 182 (2014).

${ }^{15}$ F. P. Wenzl, P. Pachler, E. J. W. List, D. Somitsch, P. Knoll, S. Patil, R. Guentner, U. Scherf, and G. Leising, Phys. E 13(2-4), 1251 (2002).

${ }^{16}$ S. T. Parker, J. D. Slinker, M. S. Lowry, M. P. Cox, S. Bernhard, and G. G. Malliaras, Chem. Mater. 17(12), 3187 (2005); R. D. Costa, A. Pertegas, E. Orti, and H. J. Bolink, ibid. 22(4), 1288 (2010).

${ }^{17}$ A. Asadpoordarvish, A. Sandstrom, S. Tang, J. Granstrom, and L. Edman, Appl. Phys. Lett. 100(19), 193508 (2012).

${ }^{18}$ S. van Reenen, T. Akatsuka, D. Tordera, M. Kemerink, and H. J. Bolink, J. Am. Chem. Soc. 135(2), 886 (2013); M. Lenes, G. Garcia-Belmonte, D. Tordera, A. Pertegas, J. Bisquert, and H. J. Bolink, Adv. Funct. Mater. 21(9), 1581 (2011).

${ }^{19}$ N. Nabatova-Gabain, Y. Wasail, and T. Tsuboi, Curr. Appl. Phys. 6(5), 833 (2006).

${ }^{20}$ J. H. Shin, P. Matyba, N. D. Robinson, and L. Edman, Electrochim. Acta 52(23), 6456 (2007); S. Tang, W. Y. Tan, X. H. Zhu, and L. Edman, Chem. Commun. 49(43), 4926 (2013); G.-R. Lin, H.-F. Chen, H.-C. Shih, J.-H. Hsu, Y. Chang, C.-H. Chiu, C.-Y. Cheng, Y.-S. Yeh, H.-C. Su, and K.-T. Wong, Phys. Chem. Chem. Phys. 17, 6956-6962 (2015); Y. F. Hu and J. Gao, Appl. Phys. Lett. 89(25), 253514 (2006); J. Liu, I. Engquist, and M. Berggren, J. Am. Chem. Soc. 135(33), 12224 (2013). 